\title{
Evaluation of dentists' knowledge of the use of oral exfoliative cytology in clinical practice
}

\begin{abstract}
Weber Adorno SILVA ${ }^{(a)}$
Ana Paula de LIMA ${ }^{(b)}$

Luana Marotta Reis de VASCONCELLOS(b)

Ana Lia ANBINDER ${ }^{(b)}$
\end{abstract}

(a) Department of Dentistry, Universidade de Taubaté - UNITAU, Taubaté, SP, Brazil.

(b)Department of Bioscience and Oral

Diagnosis, Instituto de Ciência e Tecnologia

- ICT, Univ Estadual Paulista - UNESP, São

José dos Campos, SP, Brazil.
Declaration of Interests: The authors certify that they have no commercial or associative interest that represents a conflict of interest in connection with the manuscript.

\section{Corresponding Author:}

Ana Lia Anbinder

E-mail: ana.anbinder@ict.unesp.br

DOI: 10.1590/1807-3107BOR-2014.vol28.0010 Epub XXX XX, 2014

Submitted: May 27, 2013

Accepted for publication: Dec 11, 2013

Last revision: Feb 17, 2014

\begin{abstract}
Oral exfoliative cytology (EC) is a rapid and practical complementary test that can be used in the diagnosis of various diseases. The objectives of this study were to assess dentists' knowledge of EC and to disseminate information on the technique. The study included 240 dentists from the city of Anápolis (Goiás, Brazil) who answered a questionnaire regarding demographic data and data relating to EC and who then received information on the technique. The data revealed that $26.92 \%$ of the dentists did not know about EC. Among those who reported knowledge of EC, $33.91 \%$ did not know the procedures for performing the technique, and $85.38 \%$ had no experience with EC. In addition, $54.09 \%$ of the answers regarding the instrument used to collect the material and $56.82 \%$ of the answers concerning suitable fixatives were inappropriate. Although $73.02 \%$ of the dentists adequately identified the pathologies for which EC is recommended, it was concluded that the respondents had poor knowledge of EC. There is a need to increase dentists' awareness of this subject and of EC's use in diagnostic practices.
\end{abstract}

Keywords: Cytodiagnosis; Dentist's Practice Patterns; Questionnaires; Oral Medicine.

\section{Introduction}

Exfoliative cytology (EC) is a complementary test that can be used to diagnose various oral diseases, such as squamous cell carcinoma, ${ }^{1,2,3,4}$ potentially malignant disorders, ${ }^{5}$ pemphigus, herpes, paracoccidioidomycosis, candidiasis and hairy leukoplakia, ${ }^{6}$ as well as to assist in monitoring dysplastic areas. ${ }^{7}$ In addition to oral biopsy, which is the gold standard for oral diagnosis, EC is a simple and rapid technique that is inexpensive and minimally invasive and requires no anesthesia; thus, EC is well received by patients, ${ }^{1}$ which helps professionals in diagnosing and conducting follow-up.

The EC procedure can be started by rinsing the mouth with water to remove food debris and mucus. The cells are collected, preferably using a metal spatula or a cytobrush, and the material is placed on a glass slide (smear). After fixation of the smear, the slides are sent for cytological analysis. ${ }^{8}$

Oral cancer still has high levels of incidence and mortality in Brazil, where most cases are diagnosed at later stages of the disease. ${ }^{9}$ However, many dentists have shown a lack of interest in or a lack of 
knowledge of this topic, ${ }^{9,10}$ and there is a need for interventions in professional education. Faced with this situation, we evaluated dental professionals' knowledge regarding this complementary test. In addition, we disseminated information on EC techniques.

\section{Methodology}

Two hundred forty dentists from the city of Anápolis, the third largest city in the state of Goiás (Brazil) with 335,032 inhabitants, ${ }^{11}$ participated in this study. The project was approved by the Research Ethics Committee of the Universidade de Taubaté (Unitau - 078/09).

A self-administered questionnaire was developed, pre-tested and hand-delivered to the participants. It consisted of multiple-choice and open questions and was divided into two parts: the first part referred to the professional's profile, and the second part referred to his or her knowledge about EC. After the participants completed the questionnaire, information was provided to them in the form of a printed manual. The data were tabulated using Sphinx software (Sphinx Brazil, Canoas, Brazil), version 5.1.0.4. After ascertaining the frequencies, knowledge of EC was correlated with the variables of sex, field of practice and education level using the chi-square test, t-test or Kruskal-Wallis test at a 5\% level of significance. Odds ratios (ORs) were calculated for statistically significant cases.

\section{Results}

A total of 240 questionnaires were collected, but 234 were considered because six dentists not practicing in the city of Anápolis were excluded. Several participants failed to answer some of the questions.

\section{Sample profile}

Among the 234 respondents, there was a majority of women (58.1\%), and the mean age was $36.14 \pm 10.51$ years $(\mathrm{n}=$ number of respondents to the question, $\mathrm{n}=233$, range $22-68$ years). The mean time in dental practice was $11.90 \pm 9.27$ years $(n=230$, range 1-37 years). The frequencies relative to field of practice are shown in Table 1.

Regarding education level, the answers were grouped into three categories: sensu stricto graduation (Master's and doctoral degrees and postdoctoral training), non-sensu stricto graduation (refresher and specialization programs) and no graduate degree. The percentages of the professionals sampled in each category were as follows: $8.1 \%$ ( $n=$ number of participants who chose the option, $n=19), 62.4 \%(n=146)$ and $28.6 \%(n=67)$, respectively. Two participants $(0.85 \%)$ did not answer this question.

\section{Knowledge of EC}

When asked whether they knew what EC is, $73.07 \%$ of the sample $(n=171)$ responded yes. No statistical difference in claiming knowledge was observed with regard to $\operatorname{sex}\left(\chi^{2}=0.034, p=0.854\right)$. The mean time

Table 1. Percentage of the sample and numbers of individuals who reported knowledge of EC in each field of practice.

\begin{tabular}{lcc}
\hline Field & Percentage of participants* & Knowledge of EC** \\
\hline General Practice & $76.49 \%(n=179)$ & 125 of 179 \\
Dentistry & $33.33 \%(n=78)$ & 55 of 78 \\
Prosthodontics & $20.51 \%(n=48)$ & 37 of 48 \\
Endodontics & $18.18 \%(n=44)$ & 30 of 44 \\
Orthodontics & $16.23 \%(n=38)$ & 21 of 38 \\
Periodontics & $12.82 \%(n=30)$ & 24 of 30 \\
Implant Dentistry & $11.96 \%(n=28)$ & 25 of 28 \\
Pediatric Dentistry & $11.11 \%(n=26)$ & 17 of 26 \\
Functional Jaw Orthopedics & $5.98 \%(n=14)$ & 11 of 14 \\
Dental Radiology and Imaging & $4.27 \%(n=10)$ & 9 of 10 \\
Maxillofacial Surgery and Traumatology & $5.55 \%(n=13)$ & 13 of 13
\end{tabular}

*Percentages of research participants $(\mathrm{N}=234$ ) in each field of practice. $\mathrm{n}$ is the number of subjects who chose the option. Some participants chose more than one alternative. ${ }^{* *}$ Number of individuals who reported knowledge of EC in each field of practice. 
in dental practice in the group that reported knowledge of EC was $11.86 \pm 8.82$ years, and the mean in the group that did not report knowledge of EC was $12 \pm 10.5$ years. No statistical difference in knowledge claimed was observed with regard to time in dental practice (t-value: $0.10 ; p=0.924$ ).

The individuals with sensu stricto graduate degrees (94.74\%) reported more knowledge of EC than individuals who attended other types of graduate programs $(68.49 \%)\left(\chi^{2}=5.68, p=0.017\right)$. The OR was calculated, and the odds of the group with sensu stricto graduate degrees declaring knowledge of EC was 8.28 times greater than that of the group with education from other types of graduate programs (OR $=8.28,95 \%$ confidence interval $[\mathrm{CI}] 1.073 \leq \mathrm{OR} \leq 63.918)$. The numbers of individuals who reported knowledge of EC relative to the field of practice are shown in Table 1. A statistical difference was found among fields of practice with regard to assertions of knowledge about EC (Kruskal-Wallis $=187.306, p=0.044)$. After applying Dunn's post hoc test, it was found that individuals who performed surgery and implants more frequently reported knowledge of EC (100\% and $89.29 \%$, respectively) than those in the field of orthodontics (55.26\%). The OR was calculated in comparing the implant dentistry and the orthodontics groups, and the odds of the implant dentistry group declaring knowledge of EC was 6.746 times greater than that of the orthodontics group $(\mathrm{OR}=6.746,95 \% \mathrm{CI} 1.736 \leq \mathrm{OR} \leq 26.221)$. The $\mathrm{OR}$ was calculated for the comparison between the surgery and orthodontics groups, and the odds of the surgery group declaring knowledge of EC was 10.524 times greater than that of the orthodontics group $(\mathrm{OR}=10.524,95 \% \mathrm{CI} 1.248 \leq \mathrm{OR} \leq 88.746)$.

The second part of the questionnaire ascertained actual knowledge of EC and was answered only by those who had responded that they knew what EC is. The results regarding the knowledge of procedures for performing EC, prior experience with the technique and the need for a mouth rinse are shown in Table 2.

Among the participants who reported the need for a mouth rinse, the products listed were saline $(41.86 \%, \mathrm{n}=18)$, chlorhexidine $(27.90 \%, \mathrm{n}=12)$, water $(20.93 \%, n=9)$ and other $(13.95 \%, n=6)$, and $9.3 \%$ $(n=4)$ did not answer.

Answers regarding the sampling instrument, the fixative and the pathologies that can be diagnosed using EC were classified as appropriate or inappropriate. Some respondents marked more than one answer, and others failed to answer some of the questions $(42.10 \%$ did not answer the sampling instrument question, 33.90\% did not answer the question regarding fixative, and $29.20 \%$ did not answer the question regarding pathologies). The non-answers were included with the inappropriate answers in the analysis because we believe that individuals did not answer due to a lack of knowledge. The percentages of appropriate answers and inappropriate/nonanswers are reported relative to the total number of answers and not to the number of respondents who answered this part of the questionnaire.

Appropriate answers regarding the sampling instruments were spatulas, plastic, metal or wood spatulas and brushes ( $45.91 \%$ of answers), and inappropriate answers included cotton swabs, blades and scalpels, among others. Regarding the fixative, the answers were also grouped into appropriate (ethanol and ethanol/ether, $43.18 \%$ of the answers) and inappropriate (formaldehyde and distilled water, among others). Formaldehyde was selected as the fixative of choice by $19.9 \%$ of the sample. Regarding the pathologies for which EC might be indicated, appropriate answers (carcinomas, paracoccidioidomycosis, pem-

Table 2. Percentage of the sample $(N=171)$ regarding the following variables: knowledge of the procedures for performing $\mathrm{EC}$, prior experience and the need for a mouth rinse before EC.

\begin{tabular}{lccc}
\hline & \multicolumn{3}{c}{ Variables } \\
\cline { 2 - 4 } Answers & Knowledge of the procedures for performing EC & Prior experience & Need for a mouth rinse \\
\hline Yes & $61.98 \%(n=106)$ & $10.52 \%(n=18)$ & $25.15 \%(n=43)$ \\
No & $33.91 \%(n=58)$ & $85.38 \%(n=146)$ & $50.29 \%(n=86)$ \\
Did not answer & $4.09 \%(n=7)$ & $4.09 \%(n=7)$ & $24.56 \%(n=42)$ \\
\hline
\end{tabular}

$\mathrm{n}$ is the number of subjects who chose each option. 
phigus, candidiasis, herpes, actinomycosis or ulcerations) accounted for $73.02 \%$ of the answers, while the remainder consisted of inappropriate answers (fibroma, mucocele, periodontitis, caries, all of the options mentioned and any unidentified lesion). The answer 'leukoplakia' was excluded from the analysis due to controversy regarding the use of EC for the diagnosis of leukoplakia. The most frequent answers were oral cancer $(49.10 \%$ of the sample), leukoplakia ( $46.78 \%$ of the sample) and candidiasis ( $40.40 \%$ of the sample).

Table 3 shows the values of $x^{2}$ and $p$ after the comparison between educational levels and appropriate and inappropriate/non-answers to the questions regarding the sampling instrument, the fixative and the pathologies for which EC is indicated. Regarding the fixative variable, statistical significance was found only when comparing the answers of individuals with non-sensu stricto graduation and no graduate degree. Individuals with no graduate degree indicated appropriate fixatives in $55.56 \%$ of the answers, while those with non-sensu stricto graduate training did so in $36.27 \%$ of their answers. The odds of the group with no graduate degree answering appropriately was 2.196 times higher than that of the non-sensu stricto graduate degree group (OR $=2.196,95 \%$ CI $1.122 \leq \mathrm{OR} \leq 4.298)$.

Table 4 shows the results of the Kruskal-Wallis test to compare the different fields of practice/specialties with regard to answers regarding the sampling instrument, fixative and pathologies for which EC is indicated.

\section{Discussion}

It was observed that $58.1 \%$ of the sample were women, corroborating data regarding the feminiza- tion of dentistry in Brazil, a finding that is consistent with the entry of more women into higher education. ${ }^{12}$

None of the participants reported practicing oral medicine, which demonstrates a lack of this type of training in the region. General practitioners might not feel comfortable performing simple diagnostic procedures. Information, including that which was disseminated with this study, would help to demystify this specialty practice.

Among those who claimed to know what EC is, $61.98 \%$ claimed to be familiar with the procedures for performing EC, but only $10.52 \%$ had prior experience. The high percentage of inappropriate answers to questions about the need for a mouth rinse, the sampling instrument, the fixative and the indicated pathologies could indicate a lack of knowledge about the subject in the portion of the population that reported knowing what $\mathrm{EC}$ is.

The need for a mouth rinse prior to the application of EC is a controversial subject. While some authors have used a mouth rinse to remove food debris and mucin, ${ }^{5,13,14}$ others have not reported using this procedure. ${ }^{2,715}$ The purpose of using a mouth rinse is to remove food debris and mucus, and this removal can be achieved with the use of saline or water. Mouthwashes can alter test results even 1 hour after use. ${ }^{16}$

A cytobrush, wooden spatula, metal spatula and cotton swab, among others, are the instruments that have been cited in the literature for EC material collection. $5,8,17,18,19$ The answer "cotton swab" was considered to be an inappropriate answer because few epithelial cells can be collected with this instrument, possibly due to its non-adhesive surface. ${ }^{19}$ The most cited instrument was the wooden spatula; however,

Table 3. Values of $\chi^{2}$ and $p$ after comparisons between education levels and the variables of sampling instrument, fixative and pathologies for which EC is indicated.

\begin{tabular}{lcccc}
\hline & \multicolumn{2}{c}{ Sensu stricto $\mathrm{x}$ non-sensu stricto } & $\begin{array}{c}\text { Non-sensu stricto } \mathrm{x} \text { no } \\
\text { graduate degree }\end{array}$ & $\begin{array}{c}\text { Sensu stricto } \mathrm{x} \text { no graduate } \\
\text { degree }\end{array}$ \\
\hline Sampling & $\chi^{2}$ & 0.01 & 3.095 & 1.414 \\
Instrument & $p$ & 0.921 & 0.078 & 0.234 \\
Fixative & $\chi^{2}$ & 0.436 & 5.357 & 0.669 \\
& $p$ & 0.509 & $0.021^{*}$ & 0.414 \\
Pathologies & $\chi^{2}$ & 0.933 & 0.061 & 0.541 \\
& $p$ & 0.334 & 0.805 & 0.462 \\
\hline
\end{tabular}

${ }^{*} p<0.05$ 
Table 4. $\mathrm{H}$ and $\mathrm{p}$ values from the Kruskal-Wallis test comparing the different fields of practice/specialties and the variables of sampling instrument, fixative and pathologies for which EC is indicated.

\begin{tabular}{lcc}
\hline & $\mathrm{H}$ & $\mathrm{p}$ \\
\hline Sampling Instrument & 5.655 & 0.843 \\
Fixative & 3.422 & 0.970 \\
Pathologies & 12.712 & 0.240 \\
\hline
\end{tabular}

using a wooden spatula can result in inadequate material being collected because the wood can absorb part of the sample, thereby reducing the quality of the smear. Some authors have recommended moistening the wooden spatula to prevent dehydration of the site to be sampled. ${ }^{17}$ The use of the cytobrush provides more even distribution of cells on the glass slide as compared to the wooden spatula, ${ }^{19}$ resulting in a smear with better homogeneity and cellularity than with a metal spatula. ${ }^{18}$

Formaldehyde was indicated by $19.9 \%$ of the sample as the fixative of choice for EC, which suggests that many dentists could be confusing EC with biopsy.

It was found that $73.02 \%$ of the answers regarding the pathologies for which diagnosis can be facilitated with the use of EC were appropriate, which indicates that, although there is little technical knowledge of EC techniques, the professionals did have knowledge about its indications.

Some individuals answered that EC is indicated for the diagnosis of leukoplakia, while others did not. As has been indicated in the literature, this subject is controversial, and we could not classify this answer as appropriate or inappropriate. Therefore, we decided to exclude that option from our analysis. There are two reasons for this controversy: first, the diagnosis of leukoplakia is made by exclusion; and second, leukoplakia is a clinical entity that can present with different histological, molecular and genetic patterns. ${ }^{20,21}$ The use of EC in leukoplakia has been questioned because the lesion is keratotic and non-ulcerated; these characteristics are associated with a contraindication of the technique. However, EC can be used for selecting the best area for biopsy in large leukoplakia lesions. Some authors have supported the use of EC in leukoplakias and have argued that signs of dysplasia and malignancy can be detected in the upper layers of the squamous epithelium due to the migration of cells from the basal layer. Thus, the degree of nuclear abnormality in the surface layers would reflect the degree of atypia of the entire epithelial thickness. ${ }^{22}$ Other authors have stated that this method is not appropriate in cases of hyperkeratotic lesions, in which the collected cells might not be representative for EC analysis. ${ }^{2}$

Some techniques have been incorporated into the concept of diagnostic cytology to increase the sensitivity and specificity of the test because these parameters have been questioned by some authors. ${ }^{2}$ Brush biopsy is a modification of EC, in which a brush is used, with pressure applied until bleeding is observed so that cells can be collected from all of the epithelial layers. ${ }^{13}$ The morphological analysis of the cells has been complemented by various techniques, such as DNA cytometry and the Oral CDX ${ }^{\circledR}$ system (which uses a brush biopsy and computer-assisted cell analysis), ${ }^{15,23}$ as well as the use of centrifuged samples. ${ }^{5}$

Regarding the assertion of knowledge of EC, a significant difference was found between individuals who performed maxillofacial and implant surgery and orthodontists. This difference might have been due to a more in-depth discussion of topics related to pathology and diagnosis in surgery programs. Our results showed that more than $80 \%$ of individuals who worked with the diagnosis of oral lesions and surgery reported knowing what EC is. When making comparisons between different education levels with regard to the professionals who gave appropriate answers, there was only a statistical significance regarding the fixative. The professionals without graduate degrees gave a greater number of appropriate answers than professionals with non-sensu stricto graduate educations, which might have been related to the tendency of specialists to focus on their own specialties and to have less interest in others.

\section{Conclusion}

The fact that $26.92 \%$ of the dentists did not know what EC is and that among those who reported knowledge, $33.91 \%$ did not know the procedures for performing EC, and $85.38 \%$ had no prior experience, demonstrates 
that the EC is not a technique that dentists generally consider. Furthermore, $54.09 \%$ of the answers regarding sampling instruments and $56.82 \%$ of the answers about fixatives were inappropriate among dentists who claimed to know what $\mathrm{EC}$ is. These findings prompt us

\section{References}

1. Mollaoglu N, Metzler P, Zenk J, Nkenke E, Neukam FW, Ries J. Prediction of recurrence using exfoliative cytology and melanoma-associated antigen-A mRNA analysis following wide excision of oral squamous cell carcinoma: short report. Cytopathology. 2011 Dec;22(6):387-91.

2. Kämmerer PW, Koch FP, Santoro M, Babaryka G, Biesterfeld $\mathrm{S}$, Brieger J, et al. Prospective, blinded comparison of cytology and DNA-image cytometry of brush biopsies for early detection of oral malignancy. Oral Oncol. 2013 May;49(5):420-6. DOI: 10.1016/j.oraloncology.2012.12.006. Epub 2013 Jan 11.

3. Maraki D, Becker J, Boecking A. Cytologic and DNA-cytometric very early diagnosis of oral cancer. J Oral Pathol Med. 2004 Aug;33(7):398-404.

4. Pérez-Sayánsm M, Somoza-Martín JM, Barros-Angueira F, Reboiras-López MD, Gándara-Vila P, Gándara Rey JM, et al. Exfoliative cytology for diagnosing oral cancer. Biotech Histochem. 2010 Apr 28;85(3):177-87. DOI: 10.3109/10520290903162730.

5. Shah P, Deshmukh R. Exfoliative cytology and cytocentrifuge preparation of oral premalignant and malignant lesions. Acta Cytol. 2012;56(1):68-73.

6. Dias EP, Picciani BLS, Santos VCB, Silva-Junior GO, Cantisano MH, Silva-Junior A. The advantages of oral cytopathology in the early diagnosis of HIV/AIDS: three case reports. Acta Cytol. 2012;56(4):453-6.

7. Ahmed HG, Omer AS, Abd Algaffar SA. Cytological study of exfoliative buccal mucosal cells of Qat chewers in Yemen. Diagn Cytopathol. 2011 Nov;39(11):796-800.

8. Ghom A, Mhaske S. Textbook of Oral Pathology. New Delhi: Jaypee Brothers Medical Publishers; 2008. 857 p.

9. Santos LC, Batista OM, Cangussu MC. Characterization of oral cancer diagnostic delay in the state of Alagoas. Braz J Otorhinolaryngol. 2010 Jul-Aug;76(4):416-22.

10. Yellowitz J, Horowitz AM, Goodman HS, Canto MT, Farooq NS. Knowledge, opinions and practices of general dentists regarding oral cancer: a pilot survey. J Am Dent Assoc. 1998 May;129(5):579-83.

11. Instituto Brasileiro de Geografia e Estatística [homepage]. Brasília (DF): Instituto Brasileiro de Geografia e Estatística; 2013 [cited 2014 Feb 10]. Available from: http://www.ibge. gov.br/home/estatistica/populacao/censo2010/tabelas_pdf/ total_populacao_goias.pdf.

12. Morita MC, Haddad AE, Araújo ME. Perfil atual e tendências do cirurgião-dentista brasileiro [Internet]. Maringá: Dental Press International; 2010 [cited 2013 Feb 1]. 96 p. Available to conclude that dentists have poor knowledge of EC, despite being able to name pathologies adequately for which EC is indicated in $73.02 \%$ of cases. Our findings thus highlight the need to increase dentists' knowledge of EC and its use in diagnostic practices.

from: http://cfo.org.br/wp-content/uploads/2010/04/PERFIL_CD_BR_web.pdf.

13. Babshet M, Nandimath K, Pervatikar S, Naikmasur V. Efficacy of oral brush cytology in the evaluation of the oral premalignant and malignant lesions. J Cytol. 2011 Oct;28(4):165-72.

14. Grover S, Mujib A, Jahagirdar A, Telagi N, Kulkarni P. A comparative study for selectivity of micronuclei in oral exfoliated epithelial cells. J Cytol. 2012 Oct;29(4):230-5.

15. Reddy SG, Kanala S, Chigurupati A, Kumar SR, Poosarla CS, Reddy BV. The sensitivity and specificity of computerized brush biopsy and scalpel biopsy in diagnosing oral premalignant lesions: a comparative study. J Oral Maxillofac Pathol. 2012 Sep;16(3):349-53.

16. Kuyama K, Yamamoto H. A study of effects of mouthwash on the human oral mucosae: with special references to sites, sex differences and smoking. J Nihon Univ Sch Dent. 1997 Dec;39(4):202-10.

17. Bibbo M. Comprehensive Cytopathology. Philadelphia: W.B. Saunders; 1991. 1101 p.

18. Queiroz JB, Lima CF, Burim RA, Brandao AA, Cabral LA, Almeida JD. Exfoliative cytology of the oral mucosa: comparison of two collection methods. Gen Dent. 2010 Sep-Oct;58(5):e196-9.

19. Jones AC, Pink FE, Sandow PL, Stewart CM, Migliorati CA, Baughman RA. The Cytobrush Plus cell collector in oral cytology. Oral Surg Oral Med Oral Pathol. 1994 Jan;77(1):95-9.

20. Lima JS, Pinto Jr DS, Sousa SOM, Corrêa L. Oral leukoplakia manifests differently in smokers and non-smokers. Braz Oral Res. 2012 Nov-Dec;26(6):543-9.

21. Brouns ER, Baart JA, Bloemena E, Karagozoglu H, van der Waal I. The relevance of uniform reporting in oral leukoplakia: definition, certainty factor and staging based on experience with 275 patients. Med Oral Patol Oral Cir Bucal. 2013 Jan 1;18(1):e19-26.

22. Böcking A, Sproll C, Stöcklein N, Naujoks C, Depprich R, Kübler NR, et al. Role of brush biopsy and DNA cytometry for prevention, diagnosis, therapy, and followup care of oral cancer. J Oncol [Internet]. 2010 Dec 20 [cited 2014 Feb 10].;2011:875959. Available from: http://www.ncbi.nlm.nih. gov/pmc/articles/PMC3010705/. DOI: 10.1155/2011/875959.

23. Sciubba JJ. Improving detection of precancerous and cancerous oral lesions. Computer-assisted analysis of the oral brush biopsy. U.S. Collaborative OralCDx Study Group. J Am Dent Assoc. 1999 Oct;130(10):1445-57. 